\title{
Correction to: Palivizumab Prophylaxis Against Respiratory Syncytial Virus Infection in Children with Immunocompromised Conditions or Down Syndrome: A Multicenter, Post-Marketing Surveillance in Japan
}

\author{
Tomoko Kashiwagi $^{1} \cdot$ Yukiko Okada $^{1} \cdot$ Ken Nomoto $^{1}$
}

Published online: 10 April 2018

(C) Springer International Publishing AG, part of Springer Nature 2018

Correction to: Pediatr Drugs 2018 20(1):97-104

https://doi.org/10.1007/s40272-017-0264-y

Page 98, Section 2.1: The following sentence, which previously read:

"Newborns, infants, or young children aged 24 months and under who have Down syndrome, and children $\leq 24$ months of age without a current hs-CHD if they had experienced persistent respiratory symptoms or regular outpatient treatment due to a respiratory tract infection in previous RSV seasons were also eligible for the study."

Should read:

"Newborns, infants, or young children aged 24 months and under who have Down syndrome (without a current hsCHD) were also eligible for the study."

The original article can be found online at https://doi.org/10.1007/ s40272-017-0264-y.

Ken Nomoto

ken.nomoto@abbvie.com

1 AbbVie GK, Mita 3-5-27, Minato-ku, Tokyo 108-6302, Japan 